University of Windsor

Scholarship at UWindsor

Physics Publications

Department of Physics

$8-2019$

\title{
A Simple and Efficient Centrifugation Filtration Method for Bacterial Concentration and Isolation Prior to Testing Liquid Specimens with Laser- Induced Breakdown Spectroscopy
}

Dylan J. Malenfanta

University of Windsor

Alexandra E. Paulick

University of Windsor

Steven J. Rehse

University of Windsor

Follow this and additional works at: https://scholar.uwindsor.ca/physicspub

Part of the Physics Commons

\section{Recommended Citation}

Malenfanta, Dylan J.; Paulick, Alexandra E.; and Rehse, Steven J.. (2019). A Simple and Efficient Centrifugation Filtration Method for Bacterial Concentration and Isolation Prior to Testing Liquid Specimens with Laser-Induced Breakdown Spectroscopy. Spectrochimica Acta Part B: Atomic Spectroscopy, 158.

https://scholar.uwindsor.ca/physicspub/195

This Article is brought to you for free and open access by the Department of Physics at Scholarship at UWindsor. It has been accepted for inclusion in Physics Publications by an authorized administrator of Scholarship at UWindsor. For more information, please contact scholarship@uwindsor.ca. 
A Simple and Efficient Centrifugation Filtration Method for Bacterial Concentration and Isolation Prior to Testing Liquid Specimens with Laser-Induced Breakdown Spectroscopy

Dylan J. Malenfant ${ }^{a}$, Alexandra E. Paulick ${ }^{a}$, Steven J. Rehse ${ }^{a, *}$

aDepartment of Physics, University of Windsor, 401 Sunset Avenue, Windsor, Ontario, Canada N9B 3P4

*Corresponding author at: Department of Physics, University of Windsor, 401 Sunset Avenue, Windsor, Ontario, Canada N9B 3P4. Tel.: +1 5192533000

E-mail address: rehse@uwindsor.ca (S.J. Rehse).

\section{HIGHLIGHTS}

- Bacteria are readily trapped on sub-micron pore size filter media

- A prototype device to hold multiple filters was designed and constructed.

- Centrifuging bacterial suspensions using the device easily collects bacterial cells.

- Removal of the filters allows access to the surface for laser spectroscopy.

GRAPHICAL ABSTRACT

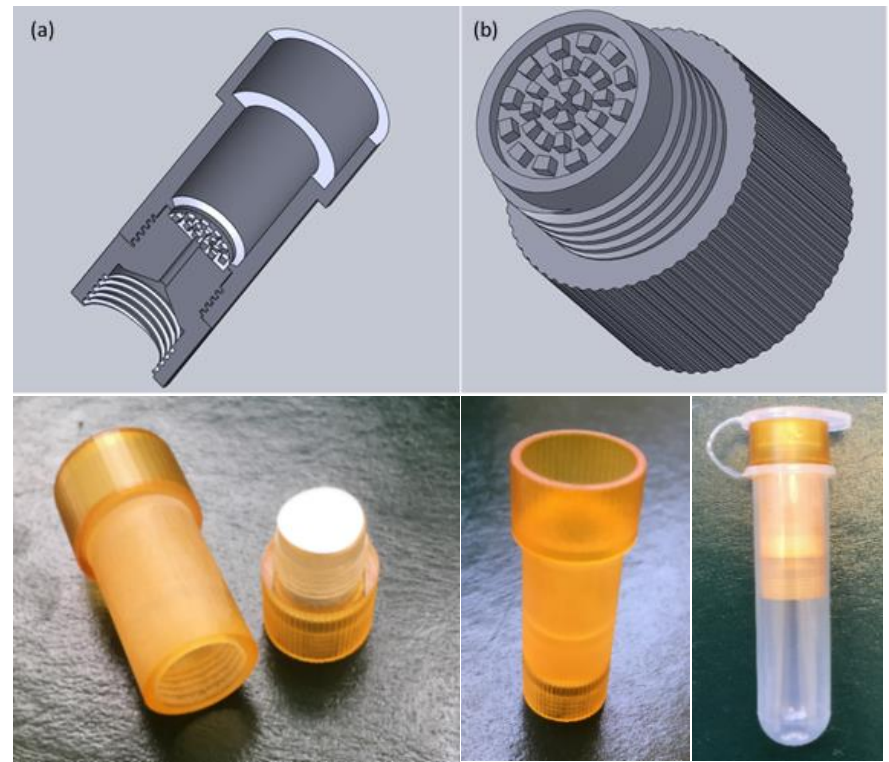




\begin{abstract}
An inexpensive filtration device was designed and constructed to rapidly concentrate bacteria in a liquid suspension on the surface of a disposable filter medium while at the same time separating the bacterial cells from larger contaminants in the suspension on the basis of their size. The device consists of a two-stage insert that is held rigidly in a standard tube during bacterial suspension centrifugation. The filters can be easily removed from the insert for subsequent testing with laser-induced breakdown spectroscopy in a process that takes only three minutes. Filter media of 0.45 micron pore size was found to capture approximately $90-95 \%$ of the cells in suspension. A limit of detection of 90,000 cells per laser shot was calculated by constructing a calibration curve from multiple suspensions of varying concentration. Deposition of the bacterial lawn across the surface of the $9.5 \mathrm{~mm}$ diameter filters was found to be uniform to within +/- 20\% of the mean as determined by the total measured optical breakdown emission. Use of 5 micron pore size filter media in the first stage of the insert was found to remove close to $100 \%$ of a 12 micron grain size tungsten contamination from the suspension while removing $10 \%$ of the bacterial cells. This mounting protocol provides a very convenient method for sample preparation that makes use of common techniques, apparatus, and procedures that would be familiar to clinicians or microbiological pathology laboratory personnel.
\end{abstract}

\title{
KEYWORDS
}

Laser-induced breakdown spectroscopy

Bacteria

Filter 


\section{Introduction}

The last thirty years have seen numerous experiments performed which have attempted to exploit the speed, utility, and flexibility of the elemental analysis technique known as laserinduced breakdown spectroscopy (LIBS) to detect, identify, or elementally characterize bacterial specimens $[1,2,3,4,5]$. The goal of these experiments has primarily been to obtain a high signalto-noise ratio LIBS spectrum which can be used to rapidly determine the elemental composition of the bacterial cells ablated by the LIBS laser pulse. This spectrum is dominated primarily by elemental emission from trace inorganic metals such as calcium, magnesium, sodium, and phosphorus, as well as other elements such as carbon and potassium [6]. Molecular emissions are also commonly observed in such spectra [7].

It has been previously noted that great care must be taken to determine how best to prepare, deposit, and sample bacterial cells to optimize the bacterial classification or discrimination, and that the choice of substrate upon which the cells are deposited may strongly impact the success the LIBS-based experiment [8]. In the majority of experiments conducted previously, the bacterial cells were prepared or "mounted" on a carefully selected target substrate prior to LIBS ablation to provide a stable and reproducible platform. Unfortunately, in most clinical or other real-world scenarios in which LIBS might be used in such applications, the number of bacteria, or bacterial titer, may be small, and the contributions to the LIBS spectrum from the underlying substrate which supports the deposited bacterial cells may be significantly larger than the bacterial signal, precluding detection or accurate identification. This is particularly problematic with the use of nanosecond laser pulses which do not control the axial ablation as precisely as femtosecond laser pulses [9].

Two exceptions exist which circumvent this spectral contamination problem. The first utilizes freeze-dried or lyophilized bacterial cells that are then compacted into a solid "pellet" which is an approach typically used for the LIBS testing of unknown powders or residues $[10,11,12]$. These pellets produce high intensity LIBS sparks due to their density and the absence of water 
$[13,14,15,16]$ and can even be mixed with a chemically inert binder to enhance the durability of the pellet during laser ablation [17]. Unfortunately, this lyophilization procedure requires a quantity of bacteria that would not be present in a clinical specimen and requires entirely too much time to make it a realistically competitive diagnostic technology.

The other exception to this is the testing of bacterial cells or spores in aerosol form as either a dense cloud [18], sparse cells dispersed in a dilute gas stream [19], or even as single cells levitated individually [20]. The amount of sample preparation effort this entails, the complexity of the apparatus, as well as the additional biohazards introduced also makes this inappropriate for use in a clinical setting.

While many groups have ablated live bacterial cells from culture directly on the surface of a nutrient medium $[21,22,23,24,25]$ this approach is complicated by a lack of control over cell number and contamination of the cells and spectrum with growth medium contributions. In addition, the colony itself, a loose conglomeration of cells, is not a desirable target for laser ablation, lacking mechanical rigidity and good thermal conductivity. Splashing and target disruption are common outcomes which tend to reduce shot-to-shot repeatability.

A superior choice to all of these is the use of inexpensive, disposable filter media. Other groups have made extensive use of such filters, which are fabricated from nitrocellulose paper, nylon, or other material, due to their widespread availability and their familiarity to clinical microbiologists $[7,26,27,28,29]$. The ability to quickly separate bacterial cells in a liquid suspension from the liquid itself using the micropores of the filter in their intended role is an obvious advantage.

Recently we have utilized such filter media which provide a highly uniform, extremely flat mounting surface upon which bacterial cells can be deposited to demonstrate rapid and efficient bacterial discrimination of liquid aliquots [30]. These experiments were conducted by creating a loose suspension of cells of known concentration which were then vortex-mixed to maximize the distribution of cells within the suspension. A custom-fabricated circular metal jig with three 4.7 
$\mathrm{mm}$ diameter holes drilled through it was placed on top of the circular filters and 30 microliters of suspension was deposited in each well with a micropipette. After 20 minutes of settling through the filter in a biosafety cabinet, three smooth lawns of bacteria were created in the shapes of the holes into which the liquid was pipetted [31]. While this method of deposition provided a uniform bacterial deposition, it was still relatively slow and limited the absolute volume of liquid sample that could be tested. Thirty microliters tended to fill the hole in the jig with liquid and subsequent depositions formed a layer of bacteria which effectively stopped up the pores of the filter, preventing the excess water from draining through.

To circumvent these problems, a new method was developed which utilized a custom-built centrifuge-tube insert to hold these filter media during centrifugation. The unique aspect of this insert is that the filter could be safely and trivially removed from the insert after centrifugation for testing in our LIBS apparatus. Utilizing this device and method, much larger volumes of bacteria-containing liquid could be processed for quick and easy separation of the bacterial cells from the liquid filtrate in a shorter period of time. In addition, the insert possessed a two-stage filtration assembly which allowed for the efficient separation of the bacterial cells from larger sized contaminations in the filtrate [32]. Thus, utilizing this insert and process has allowed us to achieve both isolation of the cells (from non-desired contaminants) and concentration of the cells (upon the surface of a filter medium) from a dilute suspension in a very rapid, convenient, and easy-to-use protocol that utilizes apparatus and methodologies highly familiar to microbiological or clinical personnel.

\section{Material and Methods}

\subsection{Centrifuge insert}

A centrifuge tube insert capable of holding and filtering at least $1.5 \mathrm{~mL}$ of liquid though two filters of varying pore sizes was designed using the SolidWorks 2010 CAD software (Dassault Systémes Solidworks Corporation) and two prototypes were generated via 3-D printing. The insert design 
and assembly is shown both disassembled and assembled in Fig. 1. The insert consisted of either two or three pieces, depending on whether single-stage or two-stage filtration was desired.

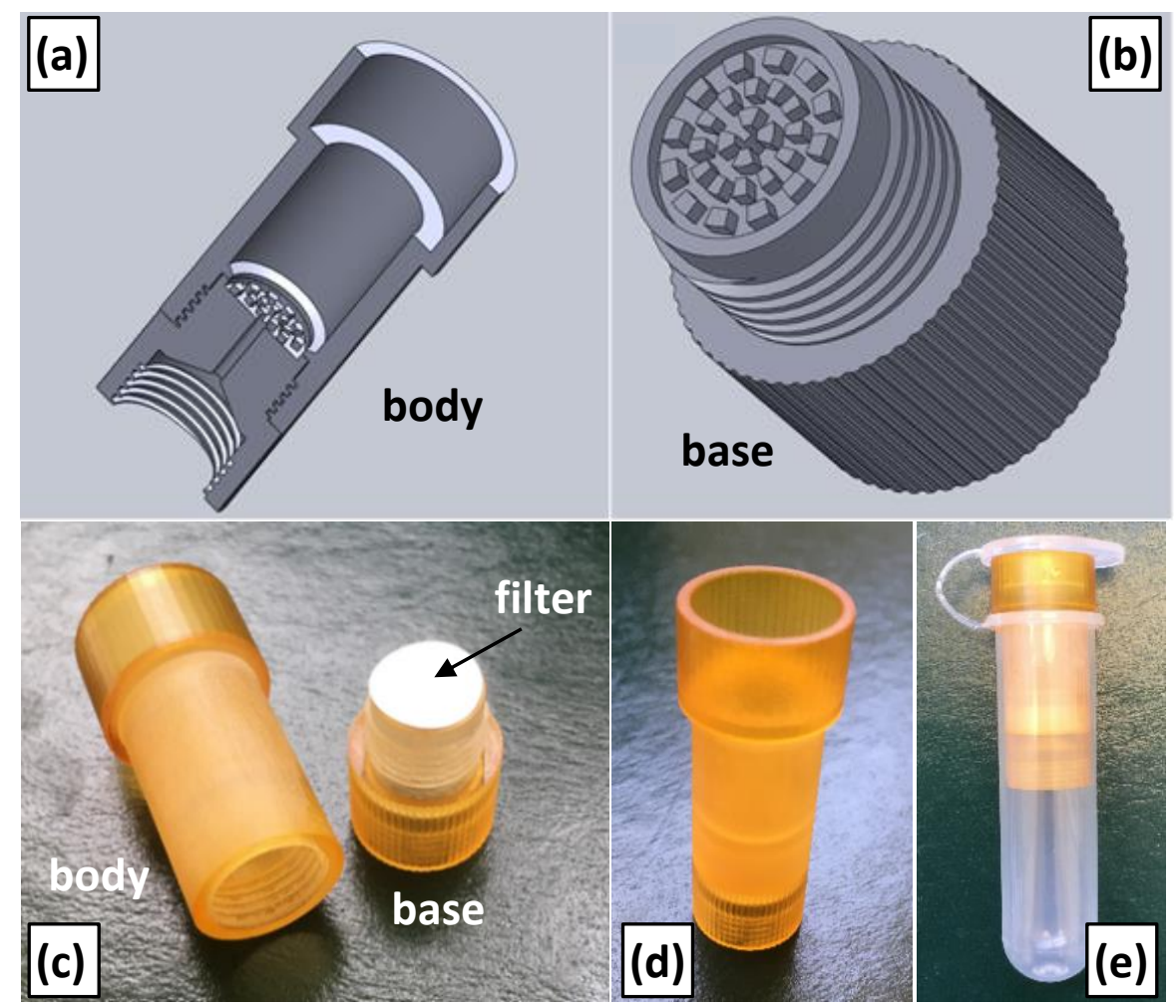

Fig. 1. Centrifuge insert design and prototype. (a) The top or "body" of the insert is threaded to accept the bottom or "base" of the insert (b). A circular filter is placed on the base and a seal is produced by the pressure generated by the threads as the base is screwed into the body. Pedestals under the filter prevent it from resting directly on a flat surface, allowing water to freely pass through the filter and through a hole in the base. Only the first filtration stage of the insert is shown. The base shown in (b) is itself threaded to allow a second identical base to screw into it holding a second filter with a different pore size. (c) Photograph of the disassembled centrifuge insert showing a filter resting in place on the base. (d) Photograph of the assembled centrifuge insert (filter is not visible within the insert) and (e) the insert secured in place by the cap of a Millipore $10 \mathrm{~mL}$ capacity centrifuge tube equipped with a hinged plastic cap.

The lightweight composite insert consisted of a cylindrical tube-shaped main body with a $14 \mathrm{~mm}$ outer diameter. The top of the main body was slightly wider at $17 \mathrm{~mm}$, allowing it to rest on the lip of a standard centrifuge tube without falling to the bottom (Fig. 1(a) and 1(e).) This centrifuge tube insert was designed to fit inside a standard $10 \mathrm{~mL}$ capacity centrifuge tube equipped with a hinged plastic cap (specifically the filtrate collection tube from an Ultrafree-CL centrifugal filter device, Millipore). The bottom of the body was threaded to allow the second piece of the insert (the base shown in Fig. 1(b)) to securely screw into it. The base of the insert served as a platform upon which the filter was placed, and screwing it into the main body created a seal around the 
edge of the filter through applied pressure. A photograph of the disassembled insert with a filter placed upon the base is shown in Fig. 1(c).

To ensure the liquid in the suspension could freely flow through the filter, the filter was supported by a solid ring around the outer circumference of the base and several small pedestal columns (visible in Fig. 1(b)) placed in three concentric rings in order to prevent the filter from resting directly on the base. A hole in the middle of the base allowed the liquid to then drain out of the insert and into the centrifuge tube in which the insert was placed.

When the base was screwed into the body, the filter was securely held on the ring of the base, forming a fairly tight seal, forcing the liquid through the filter. Fully assembled (Fig. 1(d)), the insert was $40 \mathrm{~mm}$ in height. The bottom of the base was also threaded to allow a second base piece to screw directly into it. This second base could hold a filter with a smaller pore size allowing for two-stage tiered centrifugation. This mode of operation is discussed in section 3.4.

During operation, approximately $1.5 \mathrm{~mL}$ of bacteria-containing liquid suspension was placed within the insert which was then placed within the $10 \mathrm{~mL}$ capacity Millipore filtrate collection tube and held firmly in place by a hinged cap attached to the centrifuge tube. (Fig. 1(e)). Due to the small pore size of the nitrocellulose filters, no liquid would come through the insert until centrifugation.

\subsection{Nitrocellulose filters}

The insert was designed to hold modified nitrocellulose filters. Typical experiments were conducted with $13 \mathrm{~mm}$ diameter filters (HAWP01300, $0.45 \mu \mathrm{m}$ pore size and GSWP01300, 0.22 $\mu \mathrm{m}$ pore size, Millipore-Sigma). Due to the diameter of the centrifuge tube, the inner diameter of the insert could not be designed to hold these $13 \mathrm{~mm}$ diameter filters. To properly fit on the base of the insert, the $13 \mathrm{~mm}$ diameter filter papers were cut with a punch and die set, resulting in a $9.5 \mathrm{~mm}$ diameter filter. In subsequent two-stage filtration experiments described in section 
3.4, a larger pore size filter was placed on the first-stage filtration base (SMWP01300, $5 \mu \mathrm{m}$ pore size, Millipore-Sigma) and the 0.45 micron pore size filter was placed on the second stage filtration base.

\subsection{Bacterial sample preparation}

All the experiments described in this work were conducted with non-pathogenic Escherichia coli, a rod-shaped Gram-negative microorganism of length approximately 1-2 $\mu \mathrm{m}$. The bacterial specimens were grown on plates containing tryptic soy agar (TSA) nutrient media. Following incubation, a repeatable quantity of bacteria was harvested from the surface of the nutrient plates and suspended in $1.5 \mathrm{~mL}$ of deionized water. The bacterial suspensions were stored in a refrigerator until an experiment was ready to be performed. The suspension was then thoroughly vortex-mixed to create as uniform a suspension as possible.

Concentrations of all bacterial suspensions were obtained by removing a representative quantity of suspension and transferring that volume to an optical quality cuvette for optical densitometry (absorbance) concentration measurements. This absorbance measurement was performed for

every new concentration and measured the suspended cell concentration in units of colony forming units (CFU)/mL. All samples used for absorbance measurements were discarded to avoid potential contamination.

\subsection{Centrifugation}

For all experiments, $1.5 \mathrm{~mL}$ of $E$. coli suspension of known concentration was vortexed to achieve a nominally uniform suspension and pipetted into the centrifuge insert, which was secured in the $10 \mathrm{~mL}$ Nalgene centrifuge tube. This sample was then then centrifuged for 3 minutes at 5,000 rpm (2,500 g's of force), sufficient to pull all the liquid through the filter. The insert was then removed from the centrifuge tube, disassembled, and the filter was removed from the base. The 
filter was secured to a $25 \mathrm{~mm} \times 25 \mathrm{~mm}$ piece of steel using double-sided sticky tape for LIBS testing.

\subsection{LIBS experiments}

The details of the apparatus used to obtain LIBS spectra from the highly flat and uniform filters have been previously described elsewhere [30]. $1064 \mathrm{~nm}$ laser pulses of approximately $10 \mathrm{~ns}$ duration and $8 \mathrm{~mJ}$ pulse energy were focused to approximately $75 \mu \mathrm{m}$ diameter circular spots on the surface of the filter. Ablation was performed in an argon over-pressure environment. A single shot was always sufficient to ablate all bacteria trapped on the filter as well as a layer of underlying filter media. This ablation was verified spectroscopically as subsequent laser pulses yielded spectra that were not distinguishable from blank filter spectra. It was also verified by scanning electron microscopy and high-resolution optical microscopy performed after the ablation experiments.

After every laser shot the filter was translated $0.635 \mathrm{~mm}$ to expose a new surface to the laser pulse. Three single-shot spectra were acquired and digitally averaged to minimize shot noise. Three spectra were chosen for averaging, as opposed to a larger number, to maximize the total number of spectra available for later chemometric analysis (both training and testing) which is not described in this work and also to allow a calculation of the standard deviations of subsequent measurements which were used to construct the error bars in the concentration curve presented in section 3.2. The averaging of three locations allowed the acquisition of over 50 total spectra per filter.

LIBS spectra were acquired with an Echelle spectrometer (ESA 3000, LLA instruments, Inc.) equipped with an intensified CCD camera. Spectra were acquired with a delay time of $2 \mu \mathrm{s}$ after plasma formation using an ICCD gate window of $20 \mu \mathrm{s}$ for maximum signal acquisition. Once the 
spectra were acquired, the integrated area-under-the-curve intensities of 19 backgroundsubtracted emission lines from carbon, phosphorus, magnesium, calcium, and sodium were measured. Table 1 provides the identification of these 19 emission lines used for bacterial measurements, the average LIBS emission intensities of those lines when a high concentration of bacteria was ablated upon the filter (in arbitrary units), and the LIBS emission intensities of those lines when only a blank filter (with no bacteria deposited upon it) was ablated.

\begin{tabular}{|c|c|c|c|}
\hline Element & $\begin{array}{l}\text { Wavelength } \\
(\mathrm{nm})\end{array}$ & $\begin{array}{l}\text { Average LIBS Emission } \\
\text { Intensity (AU) - Bacteria }\end{array}$ & $\begin{array}{l}\text { Average LIBS Emission } \\
\text { Intensity (AU) - } \\
\text { Blank Filter }\end{array}$ \\
\hline P I & 213.618 & 1649 & 83 \\
\hline P I & 214.914 & 879 & 98 \\
\hline C I & 247.856 & 40342 & 38082 \\
\hline P I & 253.398 & 81 & 33 \\
\hline P I & 253.560 & 387 & 46 \\
\hline P I & 255.326 & 146 & 35 \\
\hline P I & 255.491 & 79 & 37 \\
\hline Mg I & 277.983 & 141 & 42 \\
\hline $\mathrm{Mg}$ II & 279.079 & 722 & 37 \\
\hline Mg II & 279.553 & 23476 & 318 \\
\hline Mg II & 279.806 & 1306 & 34 \\
\hline $\mathrm{Mg}$ II & 280.271 & 12769 & 163 \\
\hline Mg I & 285.213 & 3343 & 112 \\
\hline $\mathrm{Ca}$ II & 317.933 & 3698 & 61 \\
\hline $\mathrm{Ca}$ II & 393.366 & 41316 & 722 \\
\hline $\mathrm{Ca}$ II & 396.847 & 19527 & 380 \\
\hline $\mathrm{Ca} \mathrm{I}$ & 422.673 & 4275 & 237 \\
\hline $\mathrm{Na} \mathrm{I}$ & 588.995 & 2751 & 837 \\
\hline $\mathrm{Na} \mathrm{I}$ & 589.593 & 1829 & 572 \\
\hline
\end{tabular}


Numerical values of the emission line intensities were obtained from the spectrometer software (ESAWIN, LLA GmbH) which performed a numeric integration of the full-width at half-maximum region of a background-subtracted peak identified by an automated peak-finding routine. Anticipated linecenters in this peak-finding routine were obtained from the NIST spectral database. Spectral background subtraction was performed prior to integration by fitting a linear function to the background region, which was defined to be 30 pixels on either side of the anticipated linecenter pixel. For these stronger peaks the linear function described the local background well and the calculated background intensity was then subtracted from the data pixel by pixel. The integrated ESAWIN software performed all of this autonomously with no userdefined input and returned spectrally-calibrated integrated areas for all nineteen lines, which were used as the emission intensities, and also the FWHM of all the emission peaks found, which were used to check for any evidence of Stark broadening, line blending, or any other unexpected deviation from the detector-limited FWHM.

\section{Results and Discussion}

\subsection{Filter bacterial retention}

Limit-of-detection (LOD) calculations required a knowledge of the number of cells ablated per laser shot. This was calculated from the known initial concentration of the bacterial suspension in the insert, the area over which the bacteria were distributed during centrifugation, and the diameter of the ablated spot. To perform this calculation, the fraction of cells caught on the filter during the centrifugation process needed to be known. Leakage through or around the pressure seal was investigated using optical densitometry on the initial suspension and the filtrate collected from the bottom of the centrifuge tube after centrifugation. Ideally all cells in the suspension should have been caught by the filter and none would have been observed in the filtrate. A calibration curve for optical densitometry measurements was constructed from known 
concentrations to enable these measurements, and a linear fit to these measurements over eight concentrations gave an $r^{2}$ value of 0.999 .

Using this fit to calculate concentrations before and after centrifugation, it was determined that $11 \%$ of the cells in the initial suspension somehow bypassed the filter and were found in the filtrate. An initial suspension concentration of $8 \times 10^{8} \mathrm{CFU} / \mathrm{mL}$ resulted in a lawn on the filter that provided $2.5 \times 10^{6} \mathrm{CFU}$ per ablation event. This was approximately the bacterial lawn density observed and used in previously described experiments [30]. This experiment was repeated for titers at one-sixth the dilution and one-ninth the dilution to ensure that the fractional loss measured was not a strong function of initial titer. These experiments yielded a loss of 7.3 and $5.3 \%$ respectively. A measurement of the scatter in repeated optical densitometry measurements on identical bacterial specimens convinced us that this scatter was within the uncertainly of those measurements due to repeatability and did not signify a significant dependence on initial concentration. It did place an uncertainty on an absolute knowledge of the number of cells ablated, however. In all cases, a loss of $11 \%$ of the cells from the initial tilter was used as a conservative estimate in all concentrations.

\subsection{Concentration curve}

A concentration curve was constructed by calculating the total observed LIBS intensity for spectra acquired from five concentrations of bacterial suspensions which spanned approximately two decades. Using a suspension with a known initial concentration, serial dilutions were created prior to centrifugation. These dilutions were centrifuged through the insert utilizing $0.22 \mu \mathrm{m}$ filter media and 35 spectra (each the average of three locations) were acquired at each concentration. The plot of these data is shown in Fig. 2, which shows the average total measured LIBS intensity as defined in section 2.5 as a function of the calculated actual number of cells ablated per laser pulse, not the suspension concentrations. Error bars represent the one-sigma standard deviation of the 35 spectra acquired at each concentration. Ablated material from the nitrocellulose filter medium always provided a strong carbon background at all concentrations as 
can be seen in the last column of Table 1, resulting in a total measured LIBS intensity for the 19 background-subtracted emission lines which never decayed to a zero reading even for a blank filter sample (the absence of any cells).

A linear fit was performed on these data with a calculated $r^{2}$ value of 0.975 . An LOD was calculated from this plot using the standard $3 \sigma / m$ definition. The LOD was determined to be $60,000 \pm 5,000$ CFU per ablation event, which was no improvement over previously utilized methods [30]. Obtaining an LOD similar to what had been measured previously with the threehole circular jig was anticipated, as the concentration of bacterial cells on the filter utilized the same physical mechanism. The concentration of the liquid suspension used to generate the centrifuge-tested sample, however, was significantly lower than when the jig was used and the sample preparation time was greatly reduced. When the uncertainties of the data points obtained from the scatter of the 35 measurements was given a direct weighting on the fit, the goodness of fit improved to an $r^{2}$ of 0.993 , but the LOD was then calculated as $90,000 \pm 9,000$ CFU per ablation event.

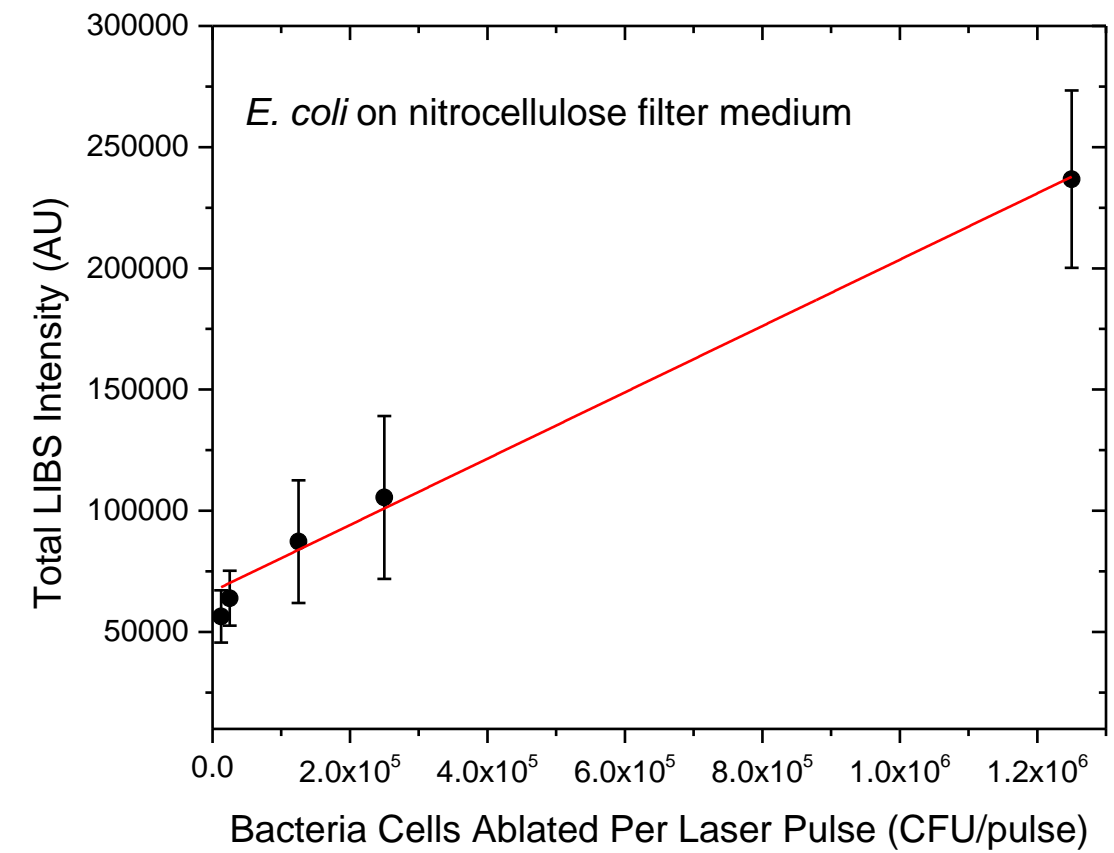

Fig. 2. Calibration curve for E. coli spectra acquired using specimens prepared at five different concentrations then collected on 0.22 micron filter media using the centrifuge insert. 


\subsection{Deposition uniformity}

During centrifugation, the filter and the insert were held at an angle off from the vertical (as is typical for a "fixed angle" centrifuge). To determine if the deposition across the surface of the filter was uniform, single shot LIBS spectra were collected from across an entire filter with sampling locations spaced in a $0.6825 \mathrm{~mm}$ (approximately 1/40 of an inch) square grid. This experiment served as a check that the total observed LIBS intensity was uniform spatially over the surface of the filter which would indicate that the deposition was regular. In addition this allowed for a comparison of the standard deviation of those measurements with the standard deviation of measurements acquired using a previously described method [30].

A false-color map was constructed from the measurements across the surface of the filter. Fig. 3 shows the variation in the total measured LIBS intensity for single-shot LIBS spectra acquired across the surface of the nitrocellulose filter after centrifugation of $E$. coli through the centrifuge insert. The color map indicates the percent difference of the total measured LIBS intensity at any one spot from the average of all measurements as a function of position on the nitrocellulose filter. Red-orange data indicate a measured intensity higher than the average. Blue-green data indicate a measured intensity lower than the average.

No strong patterns emerged in the intensities of the LIBS spectra acquired across the filter. Some systematic increase was observed with motion in the positive x-direction which may indicate a preferential deposition on the half of the filter that hangs lower in the centrifuge, but this increase spanned only approximately a $-20 \%$ to $+20 \%$ difference from the mean, which is comparable to the uncertainty of any one measurement. When the fractional standard deviation of the measured spectral lines was compared to previous data, it was seen that the signal was similarly reproducible. In previously published data, the deviation of measured LIBS intensities

for lines observed in the bacterial spectra was normally measured to be approximately $20 \%$ for small lines and $5-10 \%$ for the more intense lines. When using the centrifuge filter, these values 
were measured to be $35 \%$ and 25\%, respectively, before any averaging. Data shown in Fig. 3 is single-shot data, while bacterial data were typically acquired by averaging the measured emission from three ablation events as described in section 2.5. Since the standard deviation is inversely proportional to the square root of $N$, where $N$ is the number of measurements, this averaging can be expected to reduce these standard deviations to approximately $20 \%$ and $15 \%$, or even lower if more spectra are averaged.

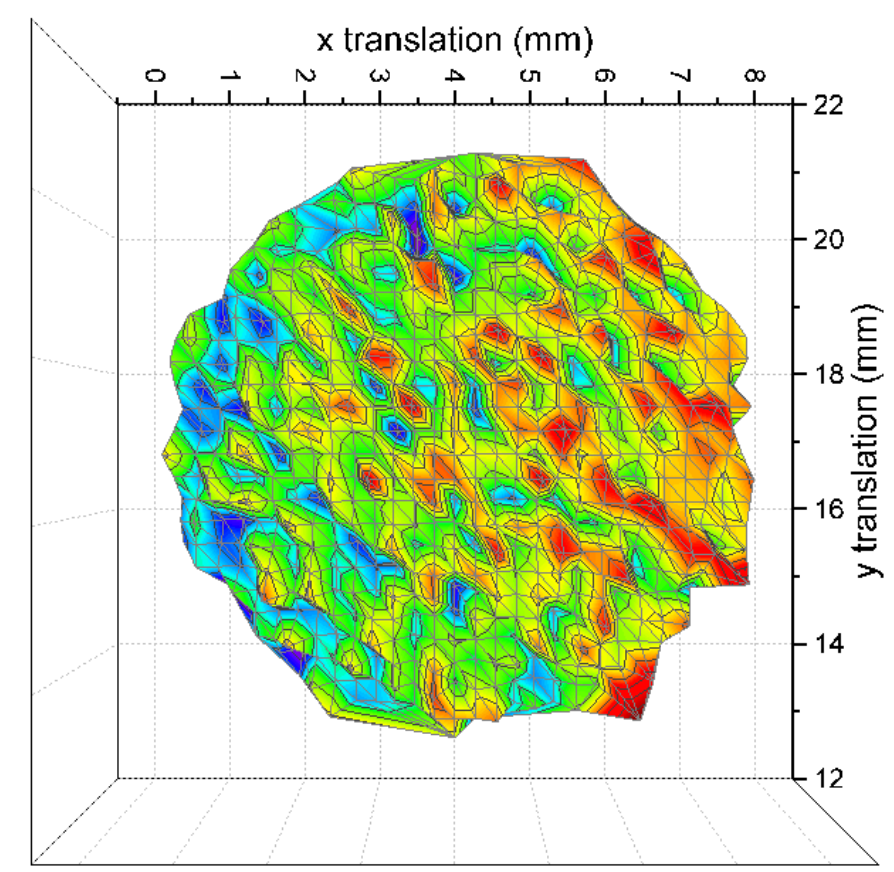

Percent variation

from the mean

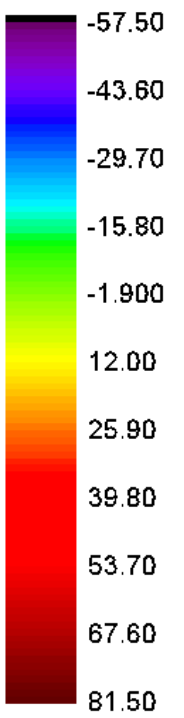

Fig. 3. The variation in the total measured LIBS intensity for single-shot LIBS spectra acquired across the surface of a nitrocellulose filter after centrifugation of $E$. coli through the centrifuge insert. Laser shots were spaced $0.6825 \mathrm{~mm}$ apart. The color map indicates the percent difference of the total measured LIBS intensity from the average of all measurements as a function of position on a nitrocellulose filter. Red-orange data indicate a measured intensity higher than the average. Blue-green data indicate a measured intensity lower than the average.

\subsection{Two-stage centrifugation}

Bacterial cells are small, approximately $1 \mu \mathrm{m}$ in size, compared to red blood cells which are one of the smallest human cells and are $\sim 6-8 \mu \mathrm{m}$, and typical eukaryotic cells which are about $10-$ $100 \mu \mathrm{m}$. This difference in size can be used advantageously to isolate bacteria from clinical specimens based on their smaller size using two filters of varying pore size. To accomplish this, 
the centrifuge tube insert was assembled with the first-stage base holding a $5 \mu \mathrm{m}$ filter and the second-stage base holding a $0.45 \mu \mathrm{m}$ filter. This is shown in Fig. 4.

To test the efficacy of the insert for the purpose of separating unwanted material from a bacterial suspension, tungsten powder (10401, Alfa Aesar) with an average particle size of $12 \mu \mathrm{m}$ was used to simulate a contaminant. Tungsten powder was chosen for its inertness, cost and availability, safety of use, ease of preparation, biologically relevant size, and elemental purity. LIBS performed on the filters yielded easily measured and identified tungsten emission lines in the LIBS spectra which were not ever observed in the bacterial spectra. This allowed for the easy identification of the presence or absence of tungsten powder on a filter as well as a quantification of the amount of tungsten deposited. Tungsten powder was added to a suspension of E. coli, vortexed, and $\sim 0.1 \mathrm{~mL}$ was pipetted into the top of the insert prior to centrifugation, which was performed with the conditions described in section 2.4.
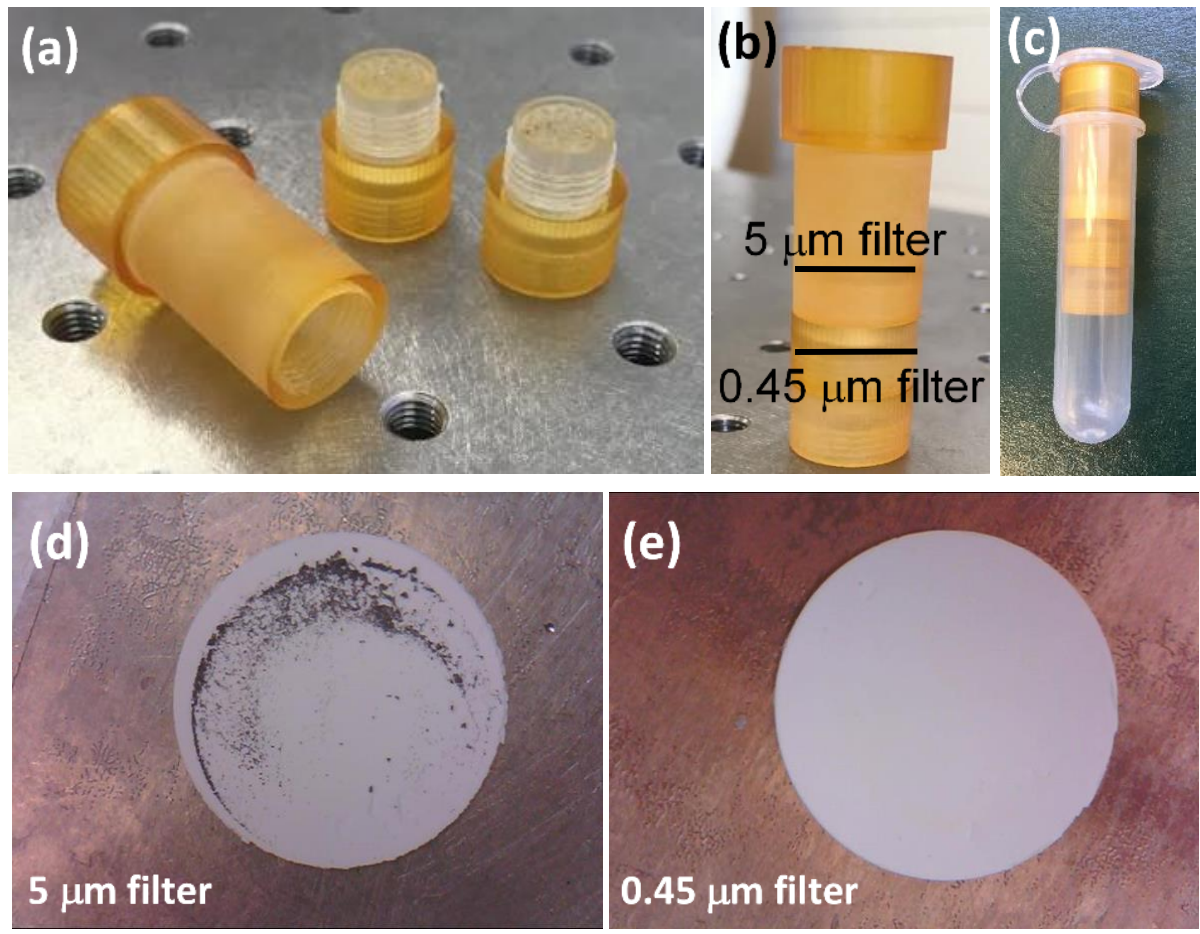

Fig. 4. Disassembled centrifuge tube insert with the main body of the insert alongside two base pieces (a). The assembled insert indicating the location and pore size of the two filters (b) and the insert in the centrifuge tube (c). After centrifugation filtration, tungsten powder with nominal grain size $12 \mu \mathrm{m}$ was readily apparent on the first-stage $5 \mu \mathrm{m}$ filter (d) while none was detected using LIBS analysis on the second-stage $0.45 \mu \mathrm{m}$ filter. 
After centrifugation, the filter papers were removed and images of them were acquired prior to LIBS testing, shown in Fig. 4(d) and 4(e). Tungsten powder was clearly observed on the $5 \mu \mathrm{m}$ filter, while none was observed on the $0.45 \mu \mathrm{m}$ filter, nor in the filtrate after centrifugation. Each filter paper was then tested with LIBS. Forty-five spectra were acquired across each filter and each of the 45 spectra was an average of three single-shot spectra acquired at different locations. Representative spectra from each filter are shown overlaid in Fig. 5. Readily identifiable tungsten emission lines were observed in the spectrum of the $5 \mu \mathrm{m}$ filter and not in the spectrum of the $0.45 \mu \mathrm{m}$ filter. Bacterial emission lines were always observed in the spectrum of the $0.45 \mu \mathrm{m}$ filter and were sometimes observed in the spectra from the $5 \mu \mathrm{m}$ filter. These results indicated that the tungsten powder was caught by the first filter while the majority of the bacteria passed through this first filter and were subsequently caught on the second filter.

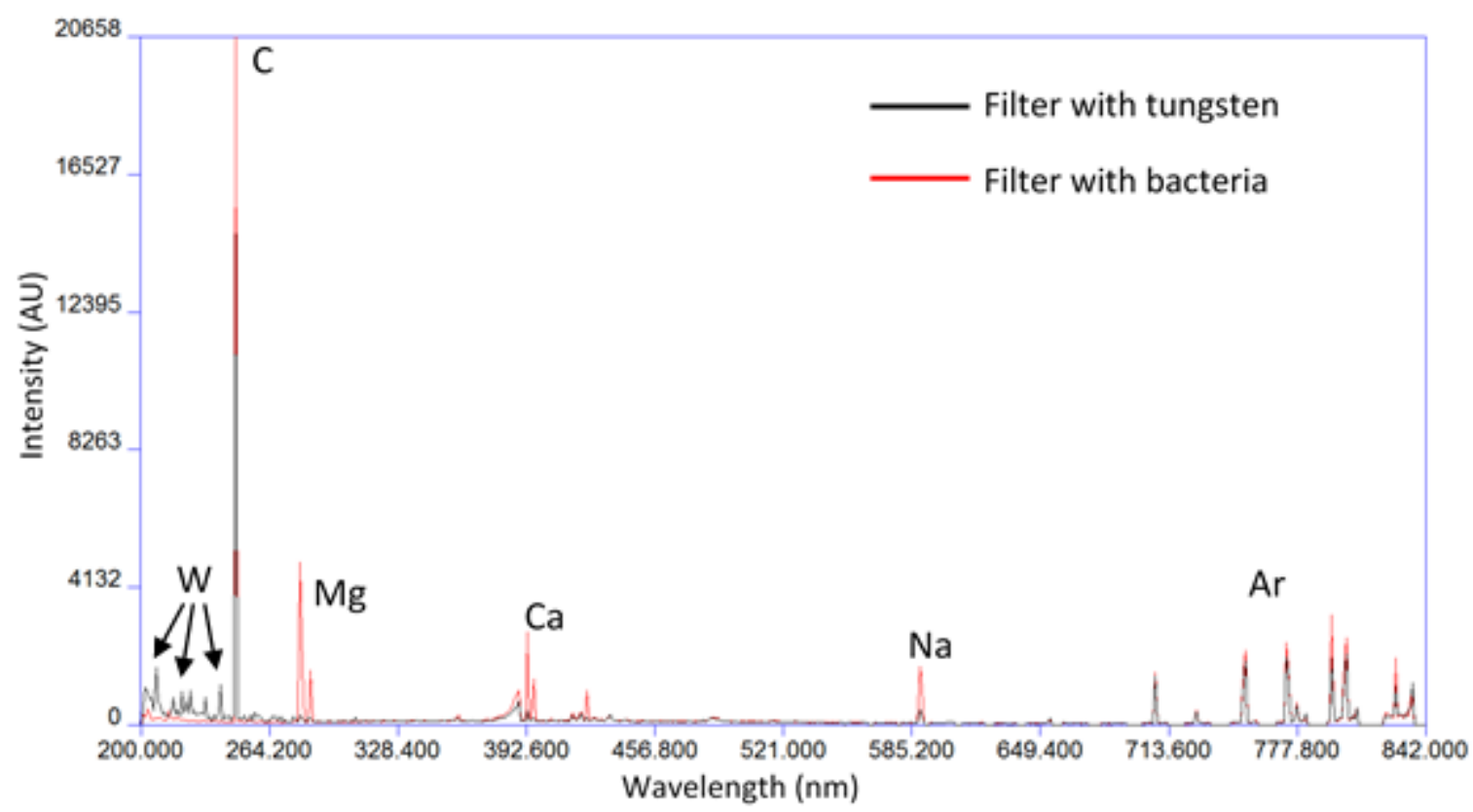

Fig. 5. LIBS spectrum from $5 \mu$ m filter (black) overlaid with spectrum from $0.45 \mu \mathrm{m}$ filter (red) after centrifugation filtration of a bacteria/tungsten powder suspension. Tungsten emission lines in the spectrum from the $5 \mu \mathrm{m}$ filter are evident in the $200-250$ $n m$ range. No tungsten lines were observed in the spectrum from the $0.45 \mu \mathrm{m}$ filter, but bacterial emission lines were evident.

To determine what fraction of the bacterial cells were inadvertently caught on the first-stage 5 $\mu \mathrm{m}$ filter, the average total LIBS intensity from the 45 spectra acquired on the filter papers was used. The total measured LIBS intensity used in this study was calculated as the sum of the 
intensities of all bacterial emission lines shown in Table 1 but not including the intensity of the observed carbon $247 \mathrm{~nm}$ line. The intensity of this line was not used because a significant fraction of this line is due to ablation of the filter medium, and this can be effected by coverage of the filter with the tungsten material. As well, the intensity of the measured carbon $247 \mathrm{~nm}$ line was different for the blank $5 \mu \mathrm{m}$ filter compared to a blank $0.45 \mu \mathrm{m}$ due to the difference in the amount of carbon ablated, which is a function of the pore size of the filter. The experiment was performed three times: once with the suspension of $E$. coli mixed with tungsten powder and twice with a suspension of just $E$. coli.

The measured LIBS bacterial signal on the $5 \mu \mathrm{m}$ filters was not the same within error as a $5 \mu \mathrm{m}$ blank control filter, indicating that some bacteria were in fact caught on the $5 \mu \mathrm{m}$ filter. In all three cases, the LIBS bacterial signal was significantly greater on the $0.45 \mu \mathrm{m}$ filter compared to the $5 \mu \mathrm{m}$ filter, indicating that the majority of the bacteria bypassed the first filter and were caught on the second one. An approximation of how much of the bacterial suspension was caught on the $5 \mu \mathrm{m}$ filter was done by calculating a ratio of the bacterial signal measured on the $5 \mu \mathrm{m}$ first-stage filter (after subtracting off the contribution from a blank control filter) to the

total bacterial signal measured on both filters (again after subtracting off any possible contribution from blank control filters). The three experiments indicated that $10 \%, 12 \%$, and $9 \%$ of the bacteria in the suspension were caught on the first filter. These values are consistent within the uncertainty of the measurement. These values are based on the assumption that all of the bacterial cells in the suspension settled on the two filter papers and none of them settled anywhere else. If this assumption was not true, these values are artificially high, thus establishing an upper bound for the percentage of bacterial cells inadvertently lost on the first-stage filter.

\section{Conclusions}

A unique two-stage centrifuge insert device has been fabricated for rapid and convenient deposition of bacterial cells on disposable and inexpensive nitrocellulose filter media from liquid 
suspensions of arbitrary concentration. The bacteria deposited in this manner formed a uniform layer of bacterial cells which could be detected and identified on the basis of their LIBS spectra.

Using a $0.22 \mu \mathrm{m}$ pore-size filter, $1.5 \mathrm{~mL}$ of suspension was centrifuge-filtered in three minutes and over $90 \%$ of the bacterial cells in the suspension were caught on the filter for subsequent LIBS testing. Single-shot LIBS spectra were easily acquired from a range of concentrations and a limit of detection with an upper limit of 90,000 cells per ablation event was calculated. Experiments are already underway which further concentrate cells in a much reduced area of the filter and an order of magnitude reduction in this limit of detection is anticipated.

The uniformity of the deposited bacterial lawn was studied by obtaining the total measured LIBS intensity from spectra acquired across the surface of the filter and the intensities were found to vary by approximately $20 \%$ from the mean which was also found to be the approximate fractional standard deviation for emission lines in single-shot spectra. Some systematic dependence on position, most likely related to the orientation of the filter relative to the fixed-angle of the centrifuge was observed. Overall, coverage was found to be quite uniform and adequate to obtain up to 45 high single-to-noise spectra from one $1.5 \mathrm{~mL}$ specimen, ideal for performing experiments with good statistics.

A two-stage filtration was performed by utilizing a $5 \mu \mathrm{m}$ pore-size filter in the first-stage of the insert and a $0.45 \mu \mathrm{m}$ pore-size filter in the second stage of the insert. Performance was evaluated by using a bacteria/tungsten powder mixture to quantify the amount of tungsten caught on both filters and the amount of bacteria caught on both filters. It was found that the first-stage filter caught $100 \%$ of the $12 \mu \mathrm{m}$ grain size tungsten (within the limit of our ability to detect tungsten on the filters and in the filtrate liquid) and an upper limit of $11 \%$ of the bacterial cells. This result needs to be confirmed with more biologically-relevant interferents, such as human eukaryotic cells like red or white blood cells. 
All experiments were performed with Gram-negative E. coli. Because the capture and retention of bacterial cells may be dependent on the cell size and morphology as well as cell envelope biochemistry, these experiments need to be reproduced with other phenotypes, such as Grampositive cocci (Staphylococcus or Streptococcus), Gram-positive rods (Bacillus subtilis), and even Gram-negative cocci (such as a Neisseria species.)

Taken together, these results indicate that even with a minor loss in available cells for testing, this mounting method provides a quick and convenient method for sample preparation that makes use of common techniques and apparatus that should be familiar to clinicians or microbiology/pathology laboratory personnel. Because the method efficiently and easily separates the bacterial cells from the liquid filtrate, it could be equally applied to clinical specimens such as blood or urine, environmental specimens such as contaminated tap water, or waters used to wash and prepare food items prior to consumption. The efficiency and ease with which large contaminants of both a biological and abiotic nature can be separated from the bacterial cells suggests that the adoption of this method prior to any laser-based interrogation of the filter medium in a wide variety of situations could be advantageous.

\section{Acknowledgements}

The authors would like to gratefully acknowledge the financial support of a Natural Sciences and Engineering Research Council of Canada Discovery grant and RTI equipment grant as well as a Canada Foundation for Innovation - Ontario Innovation Fund infrastructure grant. In addition, portions of the work discussed in this review were supported by both the University of Windsor's Outstanding Scholars program and NSERC USRA scholarships as well as a MITACS Globalink Research Internship.

[1] H.H. Telle, O. Samek, Biomedical applications of LIBS, in: A.W. Miziolek, V. Palleschi, I. Schechter (Eds.), Laser Induced Breakdown Spectroscopy. 1st ed., Cambridge University Press, Cambridge, 2006.pp. 282-313.

[2] V.K. Singh, A.K. Rai, Prospects for laser-induced breakdown spectroscopy for biomedical applications: a review, Lasers Med. Sci. 26 (2011) 673-687. https://doi.org/10.1007/s10103-011-0921-2 
[3] S.J. Rehse, H. Salimnia, A.W. Miziolek, Laser-induced breakdown spectroscopy (LIBS): an overview of recent progress and future potential for biomedical applications, J. Med. Eng. Technol. 36 (2012) 77-89. https://doi.org/10.3109/03091902.2011.645946

[4] A.K. Pathak, R.Kumar, V.K. Singh, R. Agrawal, S. Rai, A.K. Rai, Assessment of LIBS for spectrochemical analysis: a review, Appl. Spectrosc. Rev. 47 (2012) 14-40. https://doi.org/10.1080/05704928.2011.622327

[5] S.J. Rehse, Biomedical applications of LIBS, in: S. Musazzi, U. Perini (Eds.) Laser-Induced Breakdown Spectroscopy: Theory and Applications, Springer, Berlin, 2014, 457-488. https://doi.org/10.1007/978-3-642$\underline{45085-3 \quad 17}$

[6] S.J. Rehse, N. Jeyasingham, J. Diedrich, S. Palchaudhuri, A membrane basis for bacterial identification and discrimination using laser-induced break-down spectroscopy, J. Appl. Phys. 105 (2009) 102034 1-13. https://doi.org/10.1063/1.3116141

[7] M. Baudelet, L. Guyon, J. Yu, J.-P. Wolf, T. Amodeo, E. Frejafon, P. Laloi, Femtosecond time-resolved laserinduced breakdown spectroscopy for detection and identification of bacteria: A comparison to the nanosecond regime, J. Appl. Phys. 99 (2006) 084701. https://doi.org/10.1063/1.2187107

[8] R.A. Multari, D.A. Cremers, M.L. Bostian, Use of laser-induced breakdown spectroscopy for the differentiation of pathogens and viruses on substrates, Appl. Opt. 51 (2012) B57-B64. https://doi.org/10.1364/AO.51.000B57

[9] A. Assion, M. Wollenhaupt, L. Haag, F. Mayorov, C. Sarpe-Tudoran, M. Winter, U. Kutschera, T. Baumert, Femtosecond laser-induced breakdown spectrometry for $\mathrm{Ca} 2+$ analysis of samples with high spatial resolution, Applied Physics B, 77 (2003) 391-397. https://doi.org/10.1007/s00340-003-1262-z

[10] J.L. Gottfried, F.C. De Lucia Jr., C.A. Munson, A.W. Miziolek, Double-pulse standoff laser-induced breakdown spectroscopy for versatile hazardous materials detection, Spectrochim. Acta B 62 (2007) 1405-1411.

https://doi.org/10.1016/i.sab.2007.10.039

[11] E.G. Snyder, C.A. Munson, J.L. Gottfried, F.C. De Lucia Jr., B. Gullett, A.W. Miziolek, Laser-induced breakdown spectroscopy for the classification of unknown powders, Appl. Opt. 47 (2008) G80-G87.

https://doi.org/10.1007/s00216-009-2802-0

[12] R. Multari, D.A. Cremers, J.M. Dupre, J.E. Gustafson, The use of laser-induced breakdown spectroscopy for distinguishing between bacterial pathogen species and strains, Appl. Spectrosc. 64 (2010) 750-759.

https://doi.org/10.1366/000370210791666183

[13] S. Morel, N. Leone, P. Adam, J. Amouroux, Detection of bacteria by time-resolved laser-induced breakdown spectroscopy, Appl. Opt. 42 (2003) 6184-6191. https://doi.org/10.1364/AO.42.006184

[14] N. Leone, G. D'Arthur, P. Adam, J. Amouroux. Detection of bacterial deposits and bioaerosals by time-resolved laser-induced breakdown spectroscopy (TRELIBS). High Technol. Plasma Process. 8 (2004) 1-22.

https://doi.org/10.1615/HighTempMatProc.v8.i1.10

[15] M. Baudelet, J. Yu, M. Bossu, J. Jovelet, J.-P. Wolf, T. Amodeo, E. Frejafon, P. Laloi, Discrimination of microbiological samples using femtosecond laser-induced breakdown spectroscopy, Appl. Phys. Lett. 89 (2006) 163903. https://doi.org/10.1063/1.2361270

[16] J. Cisewski, E. Snyder, J. Hannig, L. Oudejans, Support vector machine classification of suspect powders using laser-induced breakdown spectroscopy (LIBS) spectral data, J. Chemometrics 26 (2012) 143-149.

https://doi.org/10.1002/cem.2422

[17] G.R. Gamble, B. Park, S.-C. Yoon, K.C. Lawrence, Effect of sample preparation on the discrimination of bacterial isolates cultured in liquid nutrient media using laser-induced breakdown spectroscopy (LIBS), Appl. Spectrosc. 70 (2016) 494-504. https://doi.org/10.1177/0003702815626679

[18] J.D. Hybl, G.A. Lithgow, S.G. Buckley, Laser-induced breakdown spectroscopy detection and classification of biological aerosols, Appl. Spectrosc. 57 (2003) 1207-1215. 
[19] P.B. Dixon, D.W. Hahn, Feasibility of detection and identification of individual bioaerosols using laser-induced breakdown spectroscopy, Anal. Chem. 77 (2005) 631-638. https://doi.org/10.1021/ac048838i

[20] S. Saari, S. Järvinen, T. Reponen, J. Mensah-Attipoe, P. Pasanen, J. Toivonen, J. Keskinen, Identification of single microbial particles using electro-dynamic balance assisted laser-induced breakdown and fluorescence spectroscopy, Aerosol Sci. Technol. 50 (2016) 126-132. https://doi.org/10.1080/02786826.2015.1134764

[21] T. Kim, Z.G. Specht, P.S. Vary, C.T. Lin, Spectral fingerprints of bacterial strains by laser-induced breakdown spectroscopy, J. Phys. Chem. B 108 (2004) 5477-5482. https://doi.org/10.1021/ip031269i

[22] D. Marcos-Martinez, J.A. Ayala, R.C. Izquierdo-Hornillos, F.J. Manuel de Villena, J.O. Caceres, Identification and discrimination of bacterial strains by laser induced breakdown spectroscopy and neural networks, Talanta 84

(2011) 730-737. https://doi.org/10.1016/i.talanta.2011.01.069

[23] S. Manzoor, S. Moncayo, F. Navarro-Villoslada, J.A. Ayala, R. Izquierdo-Hornillos, F.J. Manuel de Villena, J.O. Caceres, Rapid identification and discrimination of bacterial strains by laser-induced breakdown spectroscopy and neural networks, Talanta 121 (2014) 65-70. https://doi.org/10.1016/i.talanta.2013.12.057

[24] D. Prochazka, M. Mazura, O. Samek, K. Rebrošová, P. Pořízka, J. Klus, P. Prochazková, J. Novotný, K. Novotný, J. Kaiser, Combination of laser-induced breakdown spectroscopy and Raman spectroscopy for multivariate classification of bacteria, Spectrochim. Acta B 139 (2018) 6-12. https://doi.org/10.1016/i.sab.2017.11.004

[25] R.A. Multari, D.A. Cremers, M.L. Bostian, J.M. Durpr, J.E. Gustafson, Proof of principle for a real-time pathogen isolation media diagnostic: the use of laser-induced breakdown spectroscopy to discriminate bacterial pathogens and antimicrobial-resistant Staphylococcus aureus strains grown on blood agar, J. Pathog. 2013 (2013), 898106 111. https://doi.org/10.1155/2013/898106

[26] J.L. Kiel, E.A. Holwitt, J.E. Parker, J. Vivekananda, V. Franz, M.A. Sloan, A.W. Miziolek, F.C. DeLucia Jr, C.A. Munson, Y.D. Mattley, Specific biological agent taggants, Proc. SPIE 5795 (2005) 39-45. https://doi.org/10.1117/12.597640

[27] M. Baudelet, L. Guyon, J. Yu, J.-P. Wolf, T. Amodeo, E. Frejafon, P. Laloi, Spectral signature of native CN bonds for bacterium detection and identification using femtosecond laser-induced breakdown spectroscopy, Appl. Phys. Lett. 88 (2006) 06391. https://doi.org/10.1063/1.2170437

[28] M. Yao, J. Lin, M. Liu, Q. Li, Z. Lei, L. Huang, Identification of Escherichia coli by laser-induced breakdown spectroscopy, 2010 3rd International Conference on Biomedical Engineering and Informatics (Yantai, 2010) 302305. https://doi.org/10.1109/BMEl.2010.5639492

[29] Y. Markushin, P. Sivakumar, D. Connolly, N. Melikechi, Tag-femtosecond laser-induced breakdown spectroscopy for the sensitive detection of cancer antigen 125 in blood plasma, Anal. Bioanal. Chem. 407 (2015) 1849-1855. https://doi.org/10.1007/s00216-014-8433-0

[30] D.J. Malenfant, D.J. Gillies, S.J. Rehse, Bacterial suspensions deposited on microbiological filter material for rapid laser-induced breakdown spectroscopy identification, Appl. Spectrosc. 70 (2016) 485-493.

https://doi.org/10.1177/0003702815626673

[31] D.J. Malenfant, Influences on the Emissions of Bacterial Plasmas Generated through Nanosecond LaserInduced Breakdown Spectroscopy, University of Windsor, Windsor, 2016. https://scholar.uwindsor.ca/etd/5843

[32] A.E. Paulick, Development of Laser-Induced Breakdown Spectroscopy as a Rapid Diagnostic Tool for Bacterial Infection, University of Windsor, Windsor, 2018. https://scholar.uwindsor.ca/etd/7653/ 